\title{
Tracing the trajectories of contemporary online joking
}

\section{Tsakona}

National and Kapodistrian University of Athens, 13a, Navarinou str., Athens, 106 80, Greece

For citation: Tsakona, V. (2020). Tracing the trajectories of contemporary online joking. Media Linguistics, 7 (2), 169-183. https://doi.org/10.21638/spbu22.2020.202

Joke cycles nowadays emerge in social media networks and rely on intertextual links established among various texts/genres. Social media participants, in particular, are often inspired by current sociopolitical events and, as a response, create humorous texts which are disseminated online to convey their stances towards the events referred to and to amuse other members of social networks. Intertextuality plays a significant role in this process, as the humorous material created draws not only on serious texts about the events commented upon, but also on previous humorous material usually circulating online. The present case study involves the humorous texts produced after the unexpected landing of a commercial flight in Timişoara, Romania instead of Thessaloniki, Greece due to bad weather conditions. The event was mostly perceived as incongruous, and hence funny, by the Greek audience, so it quickly attracted media attention and generated both serious and humorous discussions in the Greek public sphere. The intertextual analysis of the data focuses on the humorous reactions to the event, in particular on the synergy between humor and intertextuality for creating and disseminating humor in online environments. More specifically, it demonstrates how social media participants exploit and reframe textual material coming from diverse sources to produce entertaining texts, attract the attention of the audience, and contribute to online discussions of current affairs. During this process, online joke cycles seem to be created by imitating -in a sense- and recontextualizing the production process of oral joke cycles, which were popular among speakers before the advent and spreading of social media. The intertextual chain traced through the proposed analysis shows how serious and humorous texts become part of a transformation process in online contexts and for entertaining purposes.

Keywords: humor, intertextuality, digital media, intertextual chains, recontextualization.

\section{Statement of the problem}

Humor is based on something that is evaluated as incongruous and unexpected in a certain sociocultural context. Humorists point to aspects of social reality that deviate from their expectations and are perceived and entextualized as such (on incongruity as the basis of humor, see [Raskin 1985; Attardo 2001]; on humor as a way of perceiving and representing reality, see among others [Mulkay 1988]). It therefore seems that different sociocultural communities create and enjoy different kinds of humor and laugh at different topics and aspects of social reality (see among others [Bremmer, Roodenburg 1997; Bell 2009: 246-249; Tsakona 2020].

(C) Санкт-Петербургский государственный университет, 2020 
Before the dawn of the digital age, jokes were mostly created and circulated orally in informal, face-to-face interactions among people who shared common experiences and sociocultural backgrounds. Such oral humorous texts often alluded to, and reproduced, widely held beliefs and stereotypes concerning social affairs (e. g. political events) and groups (e. g. ethnic groups, women). Thus, jokes allowed speakers to negotiate common values and stances towards the events or groups referred to and eventually to create consensus among them, at least when texts intended as humorous were accepted as such and not rejected. In this sense, Davies [Davies 2011: 248] was right to suggest that jokes work like a "thermometer" conveying information about the sociopolitical system generating them.

Widely circulating jokes may at some point be documented and collected in archives or edited volumes, and it is at that stage that their thematic similarities become salient and turn into a criterion for the classification into the so-called joke cycles. Joke cycles constitute folk taxonomies of jokes that were initially circulated orally and became written when their producers, collectors, and eventually researchers attempted to maintain them, thus further contributing to their dissemination. A joke cycle may eventually die out when people lost interest in developing it (on joke cycles, see [Attardo 2001: 68-78, Jorgensen 2017]; on joke cycles eventually dying out, see [Tsakona 2018b]).

In the digital age, and with speakers' increasing access to online media and networks, jokes are mostly created and disseminated in written discourse and/or through visual means. Oral jokes are gradually replaced by written jokes and memes, which refer to current social affairs and reproduce speakers' perspectives and evaluations of them, often drawing on widespread views and stereotypes. Memes, in particular, have become perhaps the most typical and popular online humorous genre and employ "script and sound, static pictures and moving images" to convey playful messages [Shifman 2007: 190]. They are considered to be prototypical instances of contemporary internet culture enhancing speaker involvement and everyday creativity, and used for the representation and dissemination of complex ideas and values, often in an unconventional manner [Shifman 2014; Wiggins, Bowers 2015]. In general, it seems that contemporary online jokes (including memes) often emerge from specific events that become well known to the public through the media, thus presupposing humorists' and recipients' familiarity with such events and the respective media representations [Tsakona 2015; 2018; 2018b; 2020; El Khachab 2016; Vásquez 2019].

Given the above, the written/visual and online character of contemporary jokes allows us to trace, document, and analyze the processes of their production and dissemination much more easily. While oral jokes of the past traveled from mouth to mouth and their different versions and routes may be lost forever for contemporary scholars, current jokes and their trajectories are frequently more accessible and may offer us useful information concerning the processes of their creation and spreading, since traces of such processes can be found in the social media and other online sources.

The present study will try to describe how online jokes are nowadays generated from events announced in the media. A key concept for this description will be that of intertextuality [Kristeva 1980; Bakhtin 1986; Fairclough 1992; Allen 2000], as I will investigate how humorists rely on media texts to create humorous ones, thus establishing intertextual links between different genres. Such links are part of intertextual chains, namely "relatively settled transformational relationships between texts" [Fairclough 1992: 
132]. The present study will investigate the humor produced online concerning a specific media event that took place at the beginning of 2019 in Greece and attracted the attention of Greek social media participants for a couple of days.

\section{History of the issue}

The multiple ways different utterances/texts may be connected with each other are extensively described in Bakhtin [Bakhtin 1986: 68-99], who underscores the fact that intertextuality infiltrates everything we say or write: our utterances/texts respond to previous utterances/texts; they reflect, recontextualize, or even re-accentuate them via implicit or explicit references. We could therefore perceive discourse as a network of interrelated texts influencing the form and/or content of one another. In this process, the role of the addressee is equally important with that of the text producer: they take each other into consideration when shaping their utterances/texts or interpretations. They make specific assumptions concerning each other's available background knowledge that needs (and is expected) to be activated to process discourse. In this sense, communication is based on the intertextual links both the producer and the addressee can trace between the text at hand and pre-existing or upcoming ones. In other words, interpreting a text presupposes the recognition and understanding of implicit or explicit intertextual references. Given that such references may or may not be accessible to all recipients, intertextuality can bring recipients closer or tear them apart, thus organizing people into communities (on intertextuality, see also [Fairclough 1992: 101-136; Allen 2000; Duff 2004: 237-239; Mazurek-Przybylska 2016: 81-83]).

Another important effect of intertextuality is the creation of intertextual chains [Fairclough 1992: 130-133]. By recontextualizing formal or content elements from one text/genre to another, speakers establish traceable connections between texts/genres, and such connections may be repeated in time and across contexts. Intertextual chains are thus created which consist of "series of types of texts which are transformationally related to each other in the sense that each member of the series is transformed into one or more of the others in regular and predictable ways" and "for strategic purposes" [Fairclough 1992: 130, 133].

Humor appears to be closely related to intertextuality in various ways. First of all, the mere concepts of incongruity/script opposition used to describe the core of humor [Raskin 1985; Attardo 1994; 2001] (see previous section) rely on intertextuality. When interpreting humorous texts, recipients evoke specific scripts, namely previous experiences and knowledge of the world (including, and/or included in, previous texts) to make sense of the humorous material at hand. Such previous intertextual experience and knowledge become the benchmark against which the second, incongruous script of interpretation creating the humorous effect surfaces. In other words, incongruity or script opposition cannot actually be established without reference to previous (con)texts, which are considered as expected, conventional, or normal in some sense. It is therefore suggested that "intertextuality lies at the heart of humor" [Attardo 2001: 71], as it helps determine what is incompatible or incongruous in a given (con)text.

It should also be noted that this intertextual dimension of humor is directly related to the fact that different sociocultural communities exploit different scripts or background knowledge to create humor, thus resulting in more or less significant differences 
in humor. It is not uncommon for different sociocultural communities not to share the same scripts or not to evoke the same background information for humorous purposes, and this may lead to misunderstandings or failure of humor, especially when it travels from one culture to another (e. g. through translation). In other words, in humorous communication, speakers are expected to be able to make the same intertextual connections for humor to be understood or successful [Bell 2015; Tsakona 2020] (see also previous section).

In this context, the notion of intertextuality has been exploited to account for joke similarity, thus becoming a criterion for classifying jokes. Jokes are more often than not based on recurring themes, settings, targets, stereotypes, public events and figures, as well as on common generic features, which enable individuals to make sense of them and to create more of them. On the basis of such common traits, jokes are classified in joke cycles (e. g. blonde, ethnic, or sexual jokes) [Attardo 2001; Jorgensen 2017].

In the present study, I will explore three different aspects of the synergy between humor and intertextuality:

1. Online jokes recontextualize news reports on specific events that are announced through the media.

2. Online jokes recontextualize other pre-existing texts that initially seem irrelevant to the main events referred to, but become relevant during the process of humor creation.

3. Online jokes are subsequently cast in different forms, thus becoming a different genre. The practice of "redoing" or recreating digital texts by other means is particularly common among social media users and significantly contributes to the online spreading of cultural artefacts such as memes [Shifman 2014; Laineste, Voolaid 2016].

Given the above, the following analysis intends to demonstrate how speakers' practices of humorously commenting on media events and disseminating such humor end up establishing intertextual chains involving different genres. It will therefore be shown how intertextuality plays a significant role in the creation and spreading of contemporary online jokes.

\section{Description of the research methodology}

The present case study is based on a joke cycle collected from the $6^{\text {th }}$ until the $8^{\text {th }}$ of January 2019. The data include online posts from the social media (mostly Facebook and Twitter) referring to the following series of events. On the night of January $4^{\text {th }}$, 2019, due to unusually heavy snowfall, the Macedonia airport of Thessaloniki, Greece was closed for several hours: no flights departed and incoming flights were directed to other airports or canceled. A Ryanair flight from London to Thessaloniki ended landing in Timişoara, Romania, a city which, we can quite safely assume, is not famous among Greeks (including the Greek passengers of the flight), unless they have travelled to Romania before or are familiar with Romanian history and culture. It should be noted here that, even though Romania and Greece are both Balkan countries, they are not neighboring ones: they are separated by Bulgaria, North Macedonia, and Serbia. Timişoara is approximately $800 \mathrm{kms}$ north from Thessaloniki, if one crosses the above-mentioned 
countries. Given that all other flights not permitted to land in Thessaloniki landed in Greek airports, the Timoşoara airport was not an obvious or expected choice for the Greek audience and passengers.

According to media reports, flight passengers were faced with an unexpected situation in an unknown territory. They started communicating with the air company and with Greek media to get help and find a way back home. A few of them booked expensive flights back to Greece through other destinations (e. g. Munich, Germany), 88 of them accepted Ryanair's offer to return to Thessaloniki by bus, while the rest 89 of them declined the offer. Eventually, on January $5^{\text {th }}$, the Greek government was forced to hire an airplane to bring the remaining passengers back from Timişoara.

Social media participants immediately decided to express their sympathetic and critical perspectives through their accounts in both serious and humorous tones. In expressing their sympathy, they mostly accused Ryanair of inadmissible practices and wrong decisions. What was framed as the company's unreliability and low quality services was related to the low fares usually charged to passengers. Greek social media users also criticized the Greek government for using state money (to hire the extra plane) for the benefit of a private, low prestige company. Others attacked the passengers and the media for exaggerated reactions to the events.

Here I will focus on the humorous posts referring to these events so as to explore the interplay between intertextuality and humor. A joke cycle of 134 humorous posts was collected including verbal jokes and memes. Most of them were collected through the

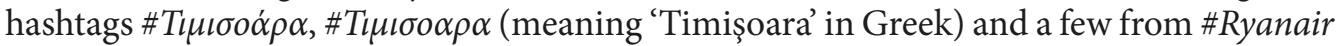
as well as from online newspaper articles which specifically reported on the humorous social media reactions to the Timişoara events. In what follows, an intertextual analysis will be performed: "the intertextual analysis identifies genres and discourses that the text draws upon, and the ways they are articulated together" [Fairclough 2000: 170]. Thus, I will try to show how humor and intertextual chains are simultaneously created.

\section{Analysis of the material}

As already mentioned, the data analysis concentrates on three aspects of the interplay between intertextuality and humor:

1) how online jokes emerge out of news reports on specific events;

2) how online jokes allude to texts initially irrelevant to the main events referred to, but becoming relevant through humor creation;

3) how online verbal jokes are cast in different forms, thus becoming a different genre.

All the humorous texts of this joke cycle explicitly or implicitly refer to the reported events concerning the flight that landed in Timişoara instead of Thessaloniki. The examples discussed here are translated into English by the author for the purposes of this study; unconventional spelling was maintained in the Greek original texts, but not reproduced in the English translations. Useful contextual or implicit information has been added by the author in square brackets. The data have also been anonymized for ethical reasons. The following examples illustrate that the change of destination is framed as incongruous, thus becoming the core of humor: 
(1)

- MANA, MAO OEIFANONIKH

- EANHINOPOYMANIKo AEEIKO NA TIAPEIE

Fig. 1 .

- Mum, I am going to Thessaloniki.

- Take a Greek-Romanian dictionary [with you] https:// twitter.com/chalk_cyclops/status/1081557174969610241?ref_ src=twsrc\%5Etfw\%7Ctwcamp\%5Etweetembed\%7Ctwterm\%5 E1081557174969610241\&ref_url=https\%3A\%2F\%2F

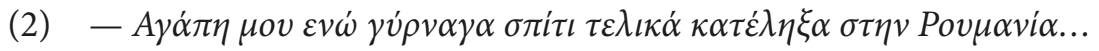

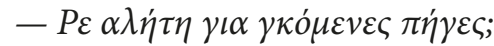

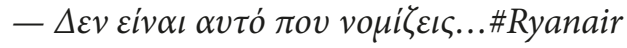

- Honey, while I was on my way home, I ended up in Romania.

- You scamp, did you go [there] for women?

- It's not what you think... \#Ryanair

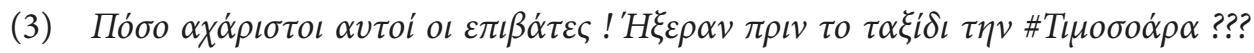

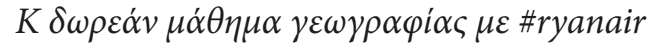

How ungrateful these passengers are! Did they even know \#Timişoara before this trip??? You also get a free geography course with \#ryanair.

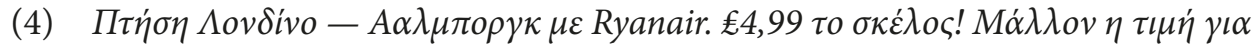

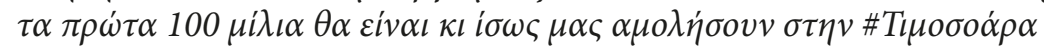

Ryanair flight from London to Aalborg. $₫ 4.99$ per trip! The price must be for the first 100 miles and perhaps they will throw us out of the plane at \#Timişoara.

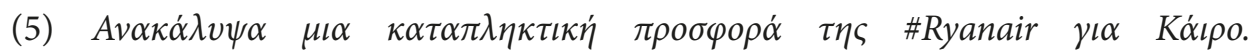

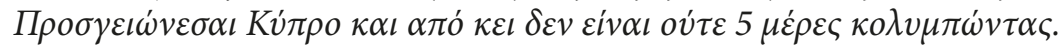

I discovered an awesome \#Ryanair offer for Cairo. You land in Cyprus and from there it's less than 5 days of swimming.

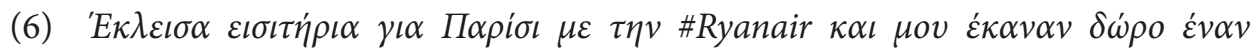

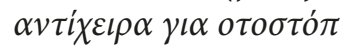

I booked tickets to Paris with \#Ryanair and they gave me a thumb as a gift to use it for hitchhiking.

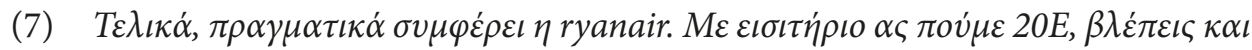

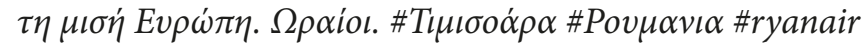


At the end, Ryanair is really a bargain. With a ticket of, say, €20 you see half Europe. Cool. \#Timişoara \#Romania \#ryanair

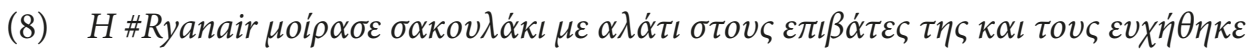

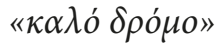

\#Ryanair distributed small bags with salt to their passengers and wished them "have a nice trip".

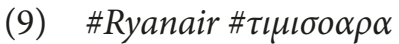

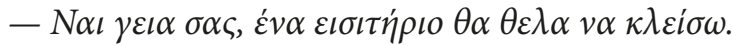

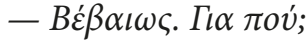

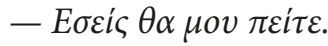

\#Ryanair \#Timişoara

- Hello, I would like to book a ticket.

- Of course. Where to?

- You tell me.

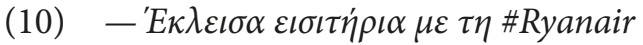

$-\Gamma i \alpha \pi o v$

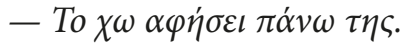

- I booked tickets with \#Ryanair.

- Where to?

- I left it up to them.

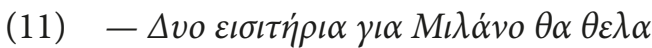

- $\Delta \varepsilon \theta \alpha \mu \alpha \varsigma \pi \varepsilon i \tau \varepsilon \varepsilon \sigma \varepsilon i \varsigma$ $\pi o v \theta \alpha \sigma \alpha \varsigma \pi \alpha \dot{\mu} \mu \varepsilon$ \#Ryanair

- I would like two tickets to Milan.

- You're not going to tell us where we'll take you. \#Ryanair

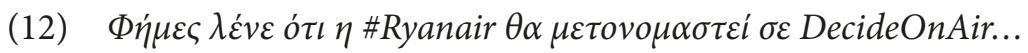

Rumor has it that \#Ryanair will be renamed to DecideOnAir...

(13) $-M \iota \alpha \theta \varepsilon \sigma \eta \theta \alpha \eta \theta \varepsilon \lambda \alpha v \alpha \kappa \lambda \varepsilon l \sigma \omega$

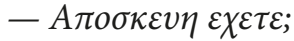

$-O \chi \iota$

$-\Theta \alpha \varphi \alpha \tau \varepsilon$

$-O \chi \iota$

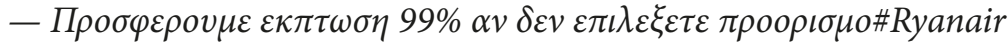

- I would like to book a ticket.

- Do you have luggage?

- No.

- Are you going to eat?

- No.

- We offer a 99\% discount if you don't choose a destination. \#Ryanair

Examples (1-2) allude to the unexpected landing of the Ryanair flight in Timişoara resulting in Greek people finding themselves in Romania and supposedly having to speak 
the local language or being forced to explain themselves to suspicious and jealous spouses. Example (3) refers to the fact that at least some Greek passengers until recently ignored what and where Timişoara is: thanks to Ryanair's decisions incongruously framed here as free geography lessons, they now know. In examples (4-8), the low prices offered by Ryanair are related to low quality services, in particular not landing in the proper destination and/or having to find other means of getting there (e. g. swimming, hitchhiking, clearing the road by throwing salt to melt the snow). Finally, in jokes (9-13), potential Ryanair passengers are not allowed or encouraged to choose their own travel destinations: the company will decide on this.

Such jokes recontextualize information which became available to the Greek audience through news reports on the Timişoara events. Those readers who may not have been familiar with the respective scripts or background knowledge could not establish the necessary intertextual connections to make sense of the jokes.

In the examples presented so far, it is news reports that are recontextualized to produce humor. In the following ones, the humorous effect also relies on intertextual references to other pre-existing texts (e. g. from mass culture or literature):

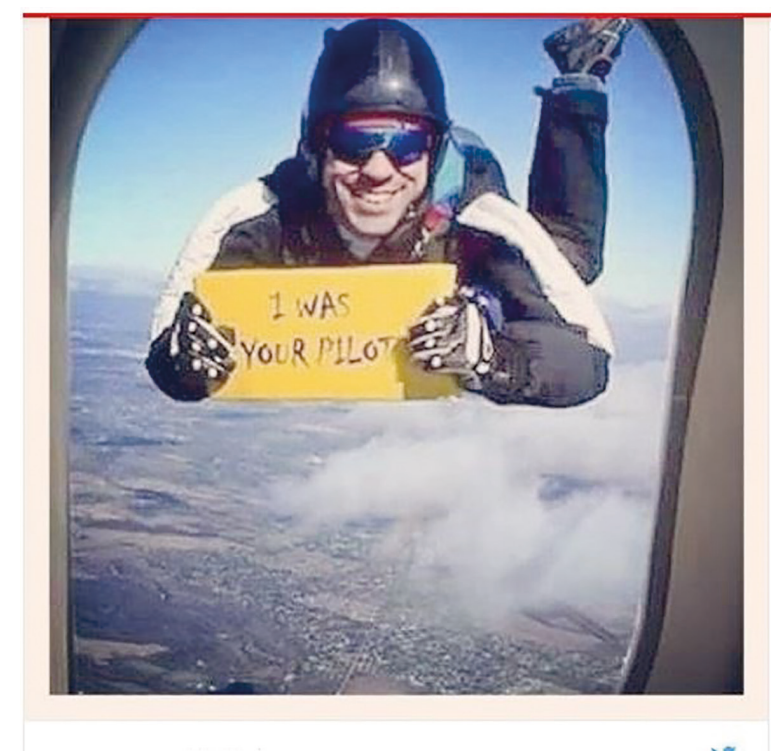

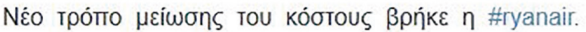

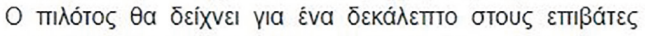

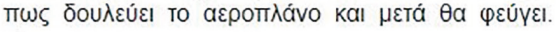

O9 3:20 PM - Jan 5, 2019

Fig. 2. \#ryanair has found a new way of lowering the prices. Within 10 minutes, the pilot will demonstrate to the passengers how the plane works and then he will leave. https:// twitter.com/stratospagdatog/status/1081540976135540736 
(15)

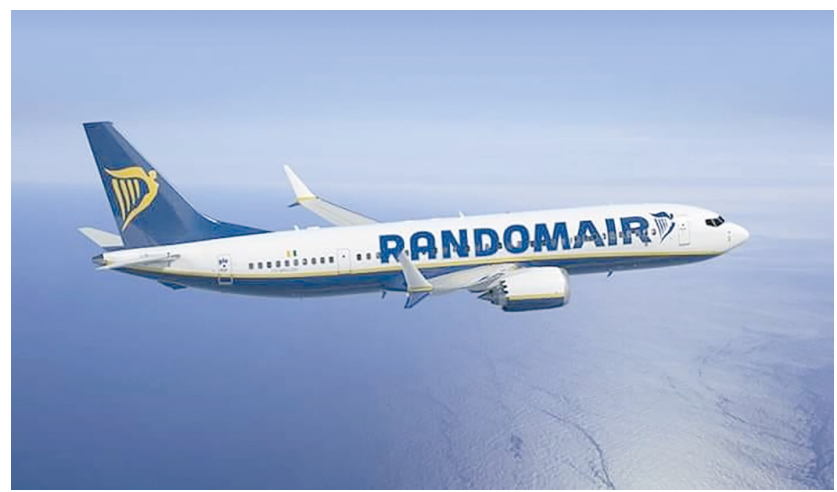

Fig. 3. https://www.facebook.com/photo.php?fbid= $2059939277382920 \& \mathrm{set}=\mathrm{pb} .100001006027234$. $2207520000 . . \&$ type $=3 \&$ theater

(16)

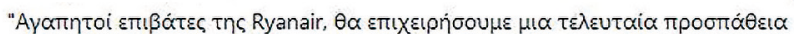

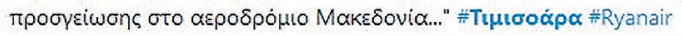

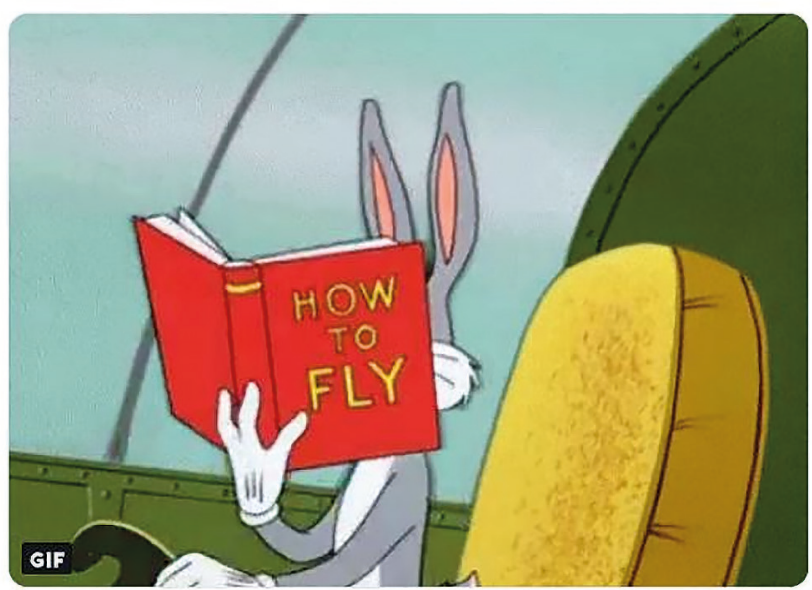

Q

ใ】 1

○ 1

Fig. 4. "Dear Ryanair passengers, we will make a final attempt to land in Macedonia airport [of Thessaloniki]..." \#Timişoara \#Ryanair. https://twitter.com/nifa1972/status/1081628131474194432

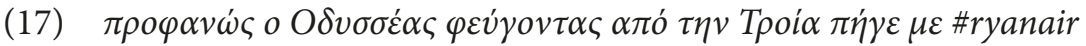

Obviously when leaving Troy Ulysses travelled with \#ryanair.

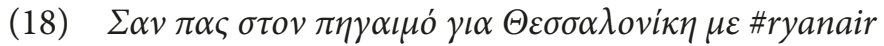

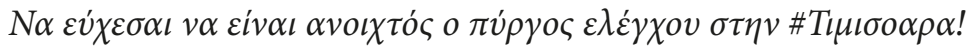


As you set out for Thessaloniki with \#Ryanair

Hope the airport traffic control tower is open at \#Timişoara!

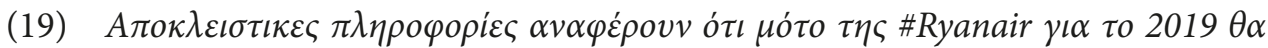

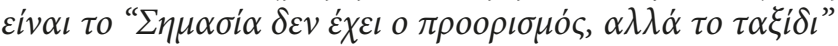

Exclusive news says that \#Ryanair's slogan for 2019 will be "The destination is not important, but the journey is".

Example (14) recontextualizes a humorous image to fit the Timişoara events: the low quality services attributed to Ryanair are exaggerated by suggesting that passengers will have to fly the plane themselves so as to reduce or even spare the pilot's salary. In example (15), a photo of a Ryanair aircraft is recontextualized so as to intertextually refer to the unexpected and "random" choice of airport for landing. Intertextuality is here combined with punning (Ryanair > Randomair) to humorously comment on the "wrong" choice of airport. A Bugs Bunny meme is recontextualized in joke (16) to refer to the pilot's allegedly limited skills (implied through the "How to Fly" manual), which led the airplane to Timişoara instead of Thessaloniki.

Highly prestigious Greek literary texts also become sources for allusions. An intertextual reference to Homer's Odyssey is employed in example (17) to frame the deviating route of the flight as incongruous. Examples (18-19) recontextualize "Ithaka", the famous Greek poem by Constantine P. Cavafy [Cavafy 1984; 1992]. The opening verses of

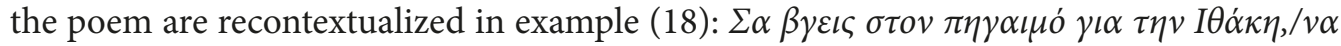

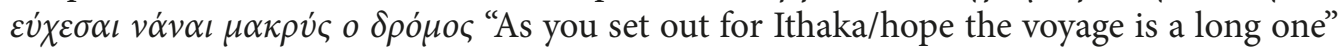

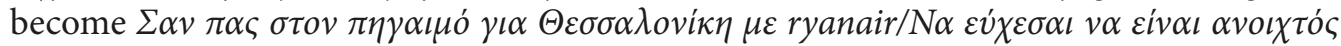

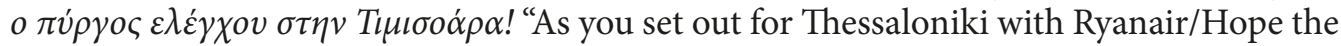
airport traffic control tower is open at Timişoara!". The same poem suggests, among other things, that one's life goals (metaphorically represented as a travelling destination, like Ulysses' Ithaka) are not that important; the experiences and knowledge one derives from the process of attaining them (metaphorically represented as a journey) are what really matters. See the following verses:

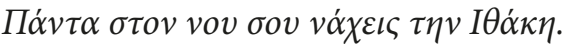

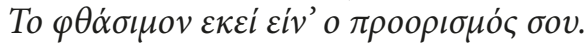

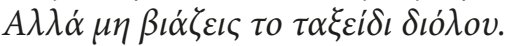

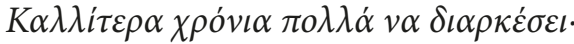

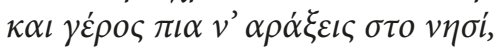

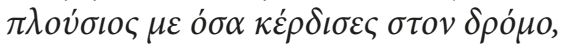

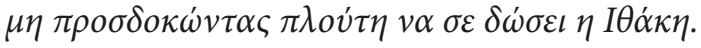

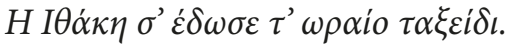

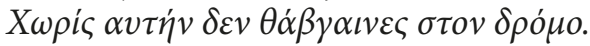

$A^{\prime} \lambda \lambda \alpha \delta \varepsilon v \varepsilon \dot{\varepsilon} \mathcal{\varepsilon} \iota \alpha \alpha \sigma \varepsilon \delta \dot{\omega} \sigma \varepsilon \iota \pi \iota \alpha$. [Cavafy 1984]

Keep Ithaka always in your mind.

Arriving there is what you are destined for.

But do not hurry the journey at all. 
Better if it lasts for years, so you are old by the time you reach the island, wealthy with all you have gained on the way, not expecting Ithaka to make you rich.

Ithaka gave you the marvelous journey.

Without her you would not have set out.

She has nothing left to give you now. [Cavafy 1992]

These verses are humorously reframed in example (19) suggesting that "The destination is not important, but the journey is". The Timişoara events are incongruously represented as a positive and rewarding adventure for the flight passengers, who supposedly gained useful and important experience and knowledge from it. The change of destination (i.e. Timişoara instead of Thessaloniki) is humorously evaluated as insignificant, after all.

In examples (14-19), joke readers are expected to be familiar not only with the events surrounding the redirected flight (as was the case with examples 1-13, too), but also with a variety of texts ranging from cartoons to poems, since the intertextual chain is enriched with texts/genres that were not originally related to these events. The "correct" or successful interpretation of such humorous texts cannot be reached unless readers are able to draw the necessary intertextual links between the texts at hand and the alluded ones.

Finally, the following examples demonstrate that verbal jokes may become memes when combined with photos or images available to social media participants. Thus, one more link is added to the intertextual chain created for humorous purposes:

(20)

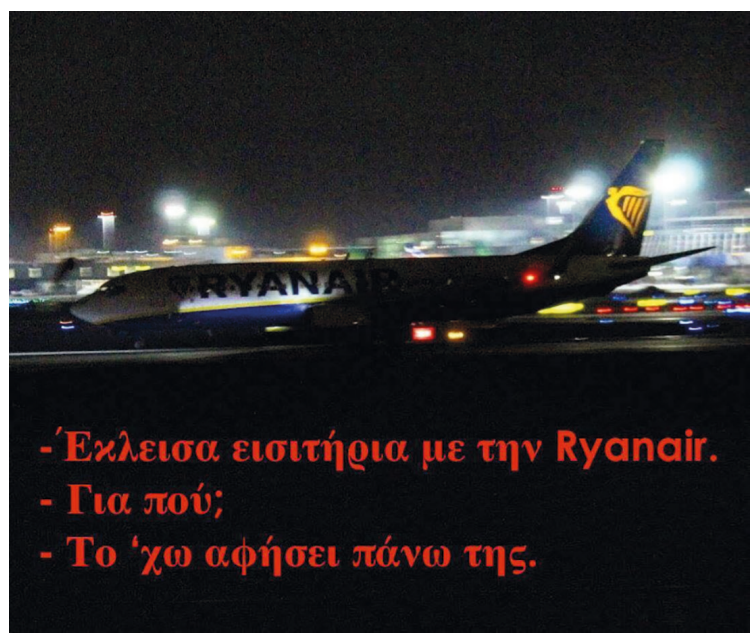

Fig. 5. - I booked tickets with Ryanair.

- Where to?

- I left it up to them. https://www.facebook.com/ photo.php?fbid=2931181076912990\&set $=$ a .4969833636661 19\&type $=3 \&$ theater 
$(21)$

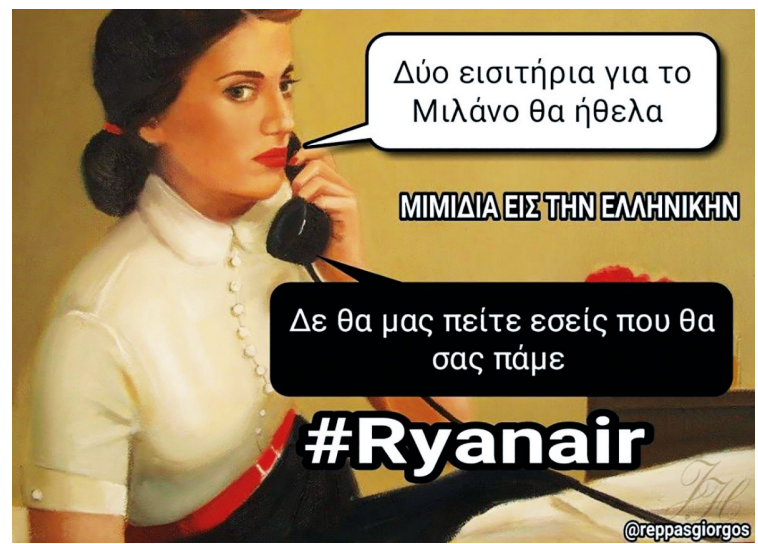

Fig. 6. - I would like two tickets to Milan.

- You're not going to tell us where we'll take you. Memes in Greek. \#Ryanair. https://www.facebook.com/ GreekMimidia/photos/a.1194590410596825/195221252816 $7939 /$ ?type $=3 \&$ theater

$(22)$

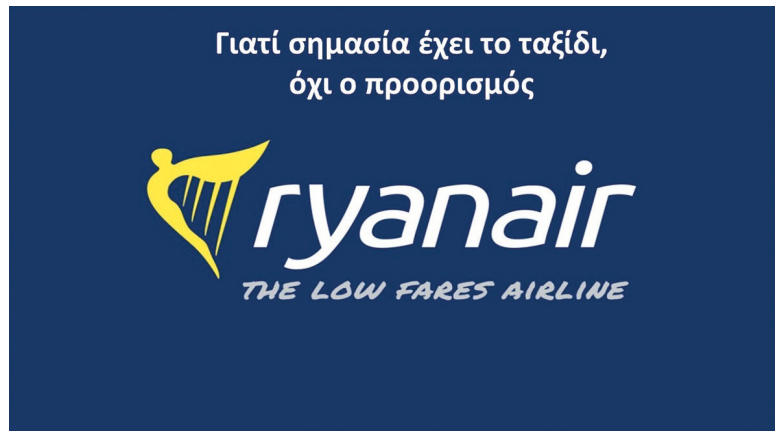

Fig. 7. Because what is important is the journey, not the destination. Ryanair. The low fares airline. https://twitter.com/ Rika_Skafida/status/1081628244217085952/photo/1

Meme (20) recontextualizes verbal example (10) (see above) and so does meme (21) for example (11). Meme (22) recreates example (19). Thus, more humor is produced and spread in multimodal form. Once again, social media participants are supposed to be familiar with the previous texts (whether news reports or others; see examples 1-19) to understand the humorous memes.

According to the data collected for the present study, such material is more often than not further disseminated through repostings and commentary by social media users. 


\section{Research results}

The aim of this paper was to account for how contemporary joke cycles including online jokes and memes are created, as well as to show that such joke cycles are part of intertextual chains connecting humorous and non-humorous texts/genres and resulting in the production and dissemination of online humor. The present analysis brings to the limelight an intertextual chain consisting of the following genres as links:

1. News reports in the media announcing specific events.

2. Posts by social media participants humorously commenting on the reported events through verbal jokes and/or memes. Some verbal jokes may be further recontextualized into memes.

3. Hashtags joining thematically related texts/posts and explicitly marking intertextual connections: social media participants create and use hashtags to bring together humorous (and non-humorous) comments by people who may be strangers to each other (see also [Zappavigna 2012]).

4. News articles in online newspapers collecting humorous posts to further disseminate and comment on the humorous reactions to the events.

5. Further comments and repostings of humorous material.

Such intertextual chains presuppose that humorists and their potential addressees share the same background knowledge or scripts: unless they evoke the same contextual information, the jokes cannot be understood. As a result, intertextuality capitalizes on specific information on social affairs, which may or may not be available or accessible to speakers (see also [Tsakona 2015; 2018a]).

\section{Conclusions}

Even though the joke cycle examined here appears to be a small-scale one (including a limited number of posts), its analysis has highlighted some differences between traditional joke cycles including mostly oral jokes and contemporary ones consisting of written or visual online material. It seems that old-fashioned tellings of oral jokes are currently and gradually replaced by posts in the social media including written jokes and memes. Contemporary online joke cycles tend to last less than traditional ones: when the alluded events are no longer part of public discussions and media reports, the respective jokes lose their popularity and eventually stop being produced (see also [Tsakona 2018b]). This may result in a rather short life-span - or at least this is what happened with the joke cycle under scrutiny: within less than a week, social media interest in the Timişoara events faded away. It therefore seems that online intertextual chains keep the reported events and the subsequent jokes "alive" for some time, until the next piece of news attracts the attention of social media humorists.

It could also be suggested that the intertextual connections between the texts/genres in contemporary joke cycles are clearly and deliberately marked by speakers: besides the explicit or implicit allusions to the reported events, they use hashtags to this end (see most of the examples analyzed in this study) or repost news articles and other material relevant to the topic at hand. Moreover, newspaper articles reporting on humorous posts clearly indicate their sources and provide hyperlinks to make them accessible to the wider audi- 
ence. The process of joke cycle creation may have not been that clearly marked or perhaps not totally conscious in oral joking, as explicit intertextual connections between jokes were often established a posteriori, for example, when collectors, editors, or researchers documented and classified them.

Drawing on Fairclough's [Fairclough 1992] conceptualization of intertextual chains, the present case study has demonstrated how social media users' effort to create and disseminate humor results in the transformation of news reports to verbal jokes and memes, often brought together by hashtags, and then in the compilation of the latter into news articles reporting on online humor. During such processes, other texts/genres also become involved to enhance the humorous effects (e. g. images, cartoons, poems), as social media participants resort to semiotic resources which they perceive as relevant to the topic at hand and shared with their potential addressees. The ensuing intertextual connections and chains (whether marked through hashtags or not) play a significant role in the creation and spreading of humor. As a result, even though online jokes can sometimes be attributed to specific jokers (e. g. in the present case, social media participants who use their real names), very quickly they become part of collective creative processes: as parts of intertextual chains, they may be widely disseminated and inspire further humorous texts.

Furthermore, Fairclough [Fairclough 1992: 133] specifically suggests that intertextual chains are established "for strategic purposes". The communicative purposes identified here involve criticizing the entities involved (mostly the air company, but also the passengers who complained in an exaggerated manner), sympathizing with the passengers' protests, sharing perspectives and laughs in the digital sphere, and perhaps projecting oneself as a digitally literate and humorous person (see also [Shifman 2014; Tsakona 2015; 2018b; El Khachab 2016; Vásquez 2019]). In addition, online humor is often employed to attract audience attention to specific events or to enhance the popularity of specific persons (including the producers of humor) as well as to bring closer people who may or may never meet offline. So, this study aligns with previous ones suggesting that humor is often employed in online environments to create ambient affiliation, namely to establish familiarity bonds among strangers through the (humorous or non-humorous) negotiation of common perspectives, values, and standpoints [Zappavigna 2012; Vásquez 2019]. A more in-depth pragmatic and/or ethnographic analysis of such data could allow us to explore in more detail speakers' motivation when posting such humorous texts online.

Finally, given that further research is necessary to examine more extensive joke cycles and more complex intertextual chains, scholarly articles on such a topic could form the next link in the above-described intertextual chain.

\section{Acknowledgements}

The author would like to thank Argiris Archakis, Salvatore Attardo, Liisi Laineste, and the anonymous reviewers for their helpful suggestions.

\section{References}

Allen, G. (2000). Intertextuality. London.

Attardo, S. (1994). Linguistic theories of humor. Berlin.

Attardo, S. (2001). Humorous texts: A semantic and pragmatic analysis. Berlin.

Bakhtin, M. (1986). Speech genres and other late essays. Austin. 
Bell, N. D. (2009). Learning about and through humor in the second language classroom. Language Teaching Research, 13 (3), 241-258.

Bell, N. D. (2015). We are not amused: Failed humor in interaction. Berlin.

Bremmer, J., Roodenburg, H. (Eds.) (1997). A cultural history of humor. From antiquity to the present day. Cambridge.

Cavafy, C. P. (1984). Poems 1897-1933. Athens. Retrieved from http://www.kavafis.gr/poems/content. asp?id=81. (In Greek)

Cavafy, C. P. (1992). Collected poems. Princeton. Retrieved from http://www.cavafy.com/poems/content. asp? cat $=1$ \&id $=74$.

Davies, C. (2011). Jokes and targets. Bloomington.

Duff, P. A. (2004). Intertextuality and hybrid discourses: The infusion of pop culture in educational discourse. Linguistics and Education, 14 (3/4), 231-276.

El Khachab, C. (2016). Living in darkness: Internet humor and the politics of Egypt's electricity infrastructure. Anthropology Today, 32 (4), 21-24.

Fairclough, N. (1992). Discourse and social change. Cambridge.

Fairclough, N. (2000). Multiliteracies and language: Orders of discourse and intertextuality. In B. Cope, M. Kalantzis (Eds.), Multiliteracies: Literacy learning and the design of social futures (pp. 159-178). London.

Jorgensen, J. (2017). \#FolkloreThursday: Joke cycle. Retrieved from https://www.patheos.com/blogs/foxyfolklorist/folklorethursday-joke-cycle.

Kristeva, J. (1980). Desire in language: A semiotic approach to literature and art. Oxford.

Laineste, L., Voolaid, P. (2016). Laughing across borders: Intertextuality of internet memes. European Journal of Humor Research, 4 (4), 26-49.

Mazurek-Przybylska, B. (2016). Intertextual face of humor: A case study of Lauren Cooper Meets Dr Who. Israeli Journal of Humor Research, 5 (1), 80-94.

Mulkay, M. (1988). On humor: Its nature and its place in modern society. Cambridge.

Raskin, V. (1985). Semantic mechanisms of humor. Dordrecht.

Shifman, L. (2007). Humor in the age of digital reproduction: Continuity and change in internet-based comic texts. International Journal of Communication, 1, 187-209.

Shifman, L. (2014). Memes in digital culture. Cambridge.

Tsakona, V. (2015). "The doctor said I suffer from vitamin $€$ deficiency": Investigating the multiple social functions of Greek crisis jokes. Pragmatics, 25 (2), 287-313.

Tsakona, V. (2018a). Intertextuality and/in political jokes. Lingua, 203, 1-15.

Tsakona, V. (2018b). Online joint fictionalization. In V. Tsakona, J. Chovanec (Eds), The dynamics of interactional humor: Creating and negotiating humor in everyday encounters (pp. 229-255). Amsterdam.

Tsakona, V. (2020). Recontextualizing humor: Rethinking the analysis and teaching of humor. Boston.

Vásquez, C. (2019). Language, creativity and humor online. London.

Wiggins, B. E., Bowers, B. G. (2015). Memes as a genre: A structurational analysis of the memescape. New Media and Society, 17 (1), 1886-1906.

Zappavigna, M. (2012). Discourse of Twitter and social media: How we use language to create affiliation on the web. London.

Received: October 25, 2019

Accepted: February 23, 2020

Author's information:

Villy Tsakona — Assistant Professor; villytsa@otenet.gr 